\title{
Las empresas sociales implicadas en la formación para desempleados. El difícil reto de la Innovación Social
}

\section{María Rosario Carvajal Muñoz}

RESUMEN: En las últimas décadas se ha incrementado notablemente la participación de organizaciones, públicas y privadas, impartiendo formación para desempleados, destacando las empresas sociales y su relación con la administración y las empresas. Recientemente, la Unión Europea está incentivando a estas organizaciones a iniciativas de innovación social para que den mejores soluciones a problemas sociales como el desempleo. Pero la innovación social requiere de la cooperación conjunta entre empresas sociales y organizaciones públicas y privadas. Desde esta perspectiva, se parte del planteamiento teórico de Pestoff, ejemplificado en su triángulo del bienestar, que relaciona las organizaciones del tercer sector, como las empresas sociales, con el Estado, el mercado y la comunidad. La investigación se realizó en la provincia de Cádiz en 2018, una zona con alta tasa de paro. Se utilizaron las siguientes técnicas de investigación: encuesta a centros colaboradores de la Junta, análisis de fuente secundaria del censo de centros de la Junta de Andalucía, 12 entrevistas en profundidad a diferentes tipologías de organizaciones, y 7 entrevistas focales a colectivos desempleados vulnerables. Entre los resultados de la investigación se constató que las organizaciones mantienen relaciones jerárquicas con la administración, escasas relaciones de cooperación entre ellas, y competencia entre centros, además de fluidas relaciones con las empresas locales, pero insuficiente inserción laboral. Estos factores no propician las condiciones para la innovación social, porque no fomentan la cooperación entre organizaciones ni favorecen los contactos con la comunidad, manteniendo en precaria situación social y laboral a los desempleados vulnerables.

PALABRAS CLAVE: Mercado, organizaciones públicas y privadas, desempleados vulnerables, administración, comunidad, innovación social.

CLAVES ECONLIT: J490, L300, L310.

Cómo citar este artículo/How to cite this article: CARVAJAL, M.R. (2021): "Las empresas sociales implicadas en la formación para desempleados. El difícil reto de la Innovación Social”, CIRIEC-España, Revista de Economía Pública, Social y Cooperativa, 102, 61-95. D0I: 10.7203/CIRIEC-E.102.16537.

Correspondencia: rosario.carvajal@uca.es, ORCID: 0000-0002-1667-3379. 


\section{Expanded abstract}

\section{The Social Enterprises in the Vocational Training for unemployed. The difficult challenge of the Social Innovation}

This paper focuses on the study of public and private organizations that provide training opportunities for the unemployed and puts special emphasis on social enterprises. This work delves into the relationships that these organizations maintain with the state, the market (companies), and the community or civil society. To this end, we follow the theoretical approach developed by Pestoff $(1998,2008)$, which is exemplified by his welfare triangle. This model began to be implemented in the 1980s under the term 'welfare-mix' and was indicative of a new approach to social and employment policy. In this context, we highlight the gradual increase in the number of training programs that social enterprises are offering worldwide, with many of these companies coming from the third sector (Bromley, Schofer \& Longhofer, 2018). We also note the interactions these companies have with the market, the community or civil society, and the state (Defourny \& Nyssens, 2012). Moreover, in the last decade, the European Union has been giving greater prominence to social innovation, which is considered by some scholars to be a key strategic plan for social enterprises to more effectively address the failures of the state and the market (Defourny \& Nyssens, 2012; Mulgan, 2006, 2007). In general terms, social innovation is based on initiatives that seek novel solutions to social problems and include the participation of the community (Murray, et al., 2010).

Based on these basic premises and more recent research, this empirical work, which was carried out in 2018 in the province of Cadiz (Spain), focuses on two objectives. The first is to analyze the typology of organizations that provide training opportunities for unemployed people, which allows us to confirm the relevance of social enterprises. The second objective is to analyze the elements that make it difficult for these training centers to adopt initiatives that allow for more autonomy and cooperation between organizations. This second objective is achieved by examining some of the theoretical assumptions outlined in the first few sections of this article, which are based on studies that highlight how cooperation between organizations favors innovation initiatives. To this end, 12 in-depth interviews were conducted with public and private organizations that provide training opportunities for unemployed people. These include non-governmental organizations, federations for disabled people, trade unions, and administrative centers, with 6 of the 12 organizations being social enterprises. We also analyzed the training programs and the type of relationships that these organizations had with each other and with the state. The results of some of the items from a survey of centers collaborating with the Junta de Andalucía (Regional Government of Andalusia) are also included, together with the results obtained from the secondary source analysis of the list of centers available 
on the Junta's website. Moreover, the information obtained for this research has been rounded out with information collected from 7 focus interviews, which used unemployed students from the training courses who had different social profiles (classified according to disability, gender, and age). The interviews with vulnerable groups provided information regarding their negative perceptions towards labor market insertion and regarding the unfavorable consequences of unemployment on their lives. The methodology used conforms to the criteria of inter-method triangulation and data triangulation, as the same research topic was approached using quantitative and qualitative techniques, which allowed for enriching data analysis on a single matter (Forni \& De Grande, 2020:166). The information obtained from the interview transcriptions was separated into analysis categories according to the theoretical assumptions developed in the first few pages of the paper and were specified as the following: A) Centers' assessment of the training program provided by the Junta de Andalucía. B) Hierarchical relations they maintain with the state. C) Horizontal relationships with similar organizations and with other types of centers. D) Characteristics of the training programs in which they participate and which may limit them.

Around $60 \%$ of the centers collaborating with the Junta de Andalucía to provide training for unemployed people in the province of Cadiz, are companies, with most of them being social enterprises for labor insertion and training. However, non-governmental organizations, foundations, federations for disabled people, and business organizations, etc. are also involved. In regard to the particularities that characterize these organizations and limit their social innovation initiatives, the following should be highlighted: a) the Junta de Andalucía establishes overly strict controls on center approval and training specialties that make it difficult to maintain measures that are flexible to changes in the environment; b) the hierarchical relations that these centers maintain with the state do not allow them to develop their own initiatives; and c) these centers have to adjust to the guidelines set by the calls for training courses, which establish a budget and a specific period of time for the presentation and execution of proposals. In addition to the above, it has been confirmed that these companies compete with each other and, consequently, there is little cooperation between the organizations involved in providing training opportunities for unemployed people. However, we must consider that these research results are representative of geographical areas with high unemployment rates, such as is the case for the province of Cadiz. The similarities and differences of these organizations compared to the types and relationships between organizations from other territories are unknown. There has also not been an in-depth study of the specific characteristics of each organization in terms of their budget and the quality of relationships they may maintain with the state, the market, and the community. Moreover, there could even be particular interests within the organizations involved in providing training opportunities beyond those established in the call for proposals.

This work also proposes several areas for future research. It raises the need to study the possible relationships between training for employment and sustainable development as education for social inclusion is a priority objective in the 2030 Agenda for Sustainable Development (2015). In this regard, social innovation is again important because, from a sustainable 
development perspective, providing training for unemployed people would mean working on both social integration and labor insertion, having them be directed towards the creation of stable jobs. This cannot be achieved automatically in an area with a high unemployment rate and, therefore, social innovation is once again a priority.

Another line of research would be the analysis of how these social enterprises have been incorporated into vocational training opportunities for unemployed people. This could be done by looking at their evolution in recent decades through the use of comparative studies within Spain and with other countries and distinguishing between the various participating social enterprises, non-governmental organizations, federations for disabled people (such as ONCE's Fundosa), and training and insertion companies. This line of research would allow us to better understand the relationship between economic, social, and political changes in the management of training opportunities for unemployed people as an active employment policy.

Finally, this work is important because it focuses attention on issues that are scarcely addressed in the literature despite their enormous importance, such as the typology of organizations and their relationships with the state, the market, and the community. Moreover, it also analyzes, in more detail, the repercussions for unemployed people of being provided with training opportunities for labor market insertion and social integration, taking into account the particularities of not only the territory but also those of vulnerable unemployed people. In this sense, it is important to note that the results highlight the need to adopt strategies that link training opportunities to the needs of companies and also to the needs of the community, making unemployed people and their environment more involved in the creation of training solutions that use innovation to favor the creation of more stable jobs.

Keywords: Market, public and private organizations, vulnerable unemployed, administration, community, social innovation. 


\section{Introducción}

Este trabajo se centra en el estudio de organizaciones públicas y privadas que imparten formación para desempleados, haciendo especial referencia a las empresas sociales. Se profundiza en las relaciones que mantienen con la administración (Estado), el mercado (empresas) y la comunidad o sociedad civil. Para ello se sigue el planteamiento teórico de Pestoff (1998, 2008), ejemplificado en su triángulo del Estado del Bienestar. Este modelo comienza a implantarse a mitad de la década de los 80 , conocido con el término inglés de Welfare-mix, indicativo de un nuevo modo de enfocar la política social y de empleo.

Se destaca el paulatino aumento que han ido asumiendo las empresas sociales en la impartición de formación para el empleo en todo el mundo, muchas provenientes del tercer sector (Bromley, Schofer y Longhofer, 2018), y resaltando su significativa interacción con el mercado, la sociedad civil o comunidad, y el Estado (Defourny y Nyssens, 2012). Estas organizaciones pueden dar soluciones a las carencias sociales dejadas por las esferas económica y política (Borzaga et al., 2017:199). En este sentido, Bidet y Spear (2005) subrayan que la formación para el empleo es una actividad fundamental para muchas empresas sociales de inserción laboral. Por su parte, Laratta y Nakagawa (2016) estudian las empresas de inserción en Japón, implicadas en la formación para desempleados con discapacidad, pero también se hacen referencias a estudios parecidos en otros continentes.

Por otro lado, la Unión Europea ha apostado firme en la última década por dar mayor protagonismo a la innovación social, considerada por algunos académicos como plan estratégico clave de las empresas sociales, junto con otras organizaciones, para afrontar de forma más eficaz las faltas dejadas por los fracasos del Estado y del mercado (Defourny y Nyssens, 2012; Mulgan, 2006, 2007). En líneas generales, la innovación social se basa en iniciativas que buscan soluciones novedosas a problemas sociales, contando con la participación de la comunidad (Murray, et al., 2010). Precisamente, en este texto se parte de la relevancia que toma la innovación social, relacionándola con los resultados obtenidos de la investigación realizada en la provincia de Cádiz en 2018.

El trabajo empírico se efectuó utilizando técnicas de investigación cuantitativa y cualitativa. Se realizaron 12 entrevistas en profundidad a organizaciones públicas y privadas que imparten formación para desempleados. Se distinguen entre organizaciones no gubernamentales, federaciones de discapacitados, sindicatos, y centros administrativos, siendo 6 de estas 12 organizaciones empresas sociales. Asimismo, se analizaron los programas formativos en los que participaban, y la tipología de relaciones que mantenían estas entidades entre sí y con la administración. Se incluyen también los resultados de algunos de los ítems de una encuesta realizada a centros colaboradores de la Junta de Andalucía en la provincia, junto con los resultados obtenidos del análisis de fuente secundaria del censo de centros disponibles en la página Web de la Junta. También se ha utilizado parte de la información obtenida de 7 entrevistas focales realizadas a alumnos desempleados de cursos de formación, con diferentes perfiles sociales, clasificados según tipo de discapacidad, género y edad. Estas entrevistas a colectivos 
vulnerables aportan información sobre sus percepciones negativas hacia la inserción laboral, y sobre las consecuencias desfavorables del desempleo para sus vidas.

En la primera sección se describirán algunas de las características de las empresas sociales, recurriendo a los autores más relevantes, y profundizando en las relaciones que mantienen con la administración (ámbito estatal), con organizaciones de la sociedad civil (ámbito comunitario) y con el ámbito empresarial. En cuanto a la innovación social, Martínez Celorrio (2015:559) subraya que la Unión Europea apuesta por este tipo de iniciativas para la política social y de empleo, principalmente a partir de 2013. También otros autores (Murray et al., 2010; Baglioni et al., 2018) insisten que la innovación social quiere dar soluciones novedosas a las faltas dejadas por los fracasos del gobierno y del mercado. Una forma de incentivar la innovación estaría en la promoción de la cooperación entre organizaciones y en una mayor participación de la comunidad. Pero se dan limitaciones que las dificultan, provenientes del contexto y de las características de las propias organizaciones (Catalá et al., 2020:1).

Justamente, los resultados del análisis de la información recabada en la provincia de Cádiz ponen el acento en las escasas relaciones que mantienen con la comunidad o sociedad civil, porque las organizaciones mantienen relaciones estrechas con el ámbito estatal y empresarial, pero disponen de escasa autonomía en la gestión de la formación y escasos contactos con la comunidad. Además, se trata de una formación para el empleo dirigida a desempleados vulnerables, que pretende la inserción laboral adecuándola a las necesidades de empresas locales, a pesar de que los resultados de inserción son escasos, dándose en esta provincia una alta tasa de paro. Esto se debe a que las organizaciones implicadas, con especial atención a las empresas sociales, supeditan sus acciones formativas a los criterios que marca la administración superior (sea la administración autonómica, central o Unión Europea), ajustada a los criterios que marca la convocatoria, conllevando, en ocasiones, a competencia entre organizaciones. Estas particularidades reducen sus posibilidades para poder adoptar iniciativas de innovación social. La innovación social podría propiciarse, por ejemplo, vinculando las acciones formativas a otras estrategias de creación de empleo estable, que contribuyan a la inserción laboral, pero también a iniciativas para la integración social de los desempleados, teniendo en cuenta que son acciones formativas dirigidas a los colectivos desempleados más vulnerables.

El texto se desglosa en cinco secciones, en la primera se analizarán las relaciones existentes entre las organizaciones del tercer sector y las empresas sociales. La segunda sección se centrará en definir y caracterizar qué es la innovación social, vinculándola a las empresas sociales en su relación con el Estado, el mercado y la comunidad, y relacionándola también con el capital social. La tercera sección analizará el papel de las organizaciones públicas y privadas, con especial atención a las empresas sociales, implicadas en la formación para colectivos vulnerables, vinculadas a iniciativas de innovación educativa. Por último, en la cuarta y quinta sección, se detallará la metodología de investigación utilizada en la provincia de Cádiz, seguida de los resultados obtenidos sobre sus limitaciones a la innovación, poniendo especial atención en las son empresas sociales. 


\section{De las organizaciones del Tercer Sector a las empresas sociales}

Las organizaciones del tercer sector se han incrementado de forma considerable durante todo el siglo XX. Bromley, Schofer y Longhofer (2018) señalan el enorme crecimiento en todo el mundo de ONGs (Organizaciones no gubernamentales) de ámbito internacional, y de organizaciones de la sociedad civil a nivel nacional, desde principios del siglo XX a la actualidad. Según estos autores, se ha dado un incremento exponencial de estas organizaciones, de 176 entidades del tercer sector en 1909 llegan a más de 60.000 en 2016. Se constata también que en las últimas décadas se dan más vinculaciones de estas organizaciones con el Estado y el mercado, en contraste con la primera mitad del siglo XX, cuando estaban más unidas a organizaciones tradicionales como la iglesia (Defourny y Pestoff, 2014:32-33). Desde la década de los 80 estas organizaciones son un complemento necesario a la sociedad, proveyendo de servicios sociales básicos a la población en interconexión con el Estado.

En España, también Vidal y Claver (2005:6) destacan su importante aumento a partir de la década de los 80 del siglo XX, un periodo que coincide con la construcción del Estado de Bienestar español. En muchos países occidentales, este incremento de organizaciones de la sociedad civil coincide con la crisis del Estado del Bienestar en la década de los 80, cuando el sector público comienza a debilitarse. A partir de entonces, la sociedad civil va asumiendo algunas de las responsabilidades del Estado del Bienestar, estableciendo redes flexibles que conectan los tres vértices del triángulo: Estado, mercado y comunidad (Baglioni, Chabanet y Persson, 2018:9).

Pero estas interconexiones de esferas entre Estado, mercado y comunidad no están exentas de conflictos (Defourny y Pestoff, 2014:34), apuntándose a tres cuestiones problemáticas. Un primer conflicto se da entre la racionalidad instrumental del mercado y la base solidaria, de valores democráticos y sociales propios del tercer sector. Un segundo conflicto se establece entre los valores universalistas de instituciones del Estado, frente a la lógica particularista de los actores más privados, incluyendo a organizaciones del tercer sector. Un tercer conflicto se produce entre las organizaciones formales y el ámbito de la comunidad, incluyendo aquí familia, amigos, barrios, redes sociales.

A principios de la década de los noventa, como subrayan Defourny y Nyssens (2012) refiriéndose a Europa, muchas de estas organizaciones del tercer sector comienzan a constituirse como empresas sociales. Este incremento coincidió con el aumento del paro y la precariedad laboral, y con el fenómeno de la globalización (Bidet y Spear, 2005:196). Es en este contexto cuando se hacen más necesarias las empresas sociales de inserción laboral. Estas empresas tienen un papel cada vez más destacado en la economía general, siendo significativas en sus interacciones con el mercado, la sociedad civil y las políticas públicas (Defourny y Nyssens, 2012). Bidet y Spear (2005:195-196) destacan su ascenso en toda Europa, insistiendo, muy particularmente, que estas empresas son parte del tercer sector, operando de forma conjunta entre el sector privado y el sector público. Esta interconexión entre las tres esferas tiene que 
ver con la transformación del Estado del Bienestar (Bidet y Spear, 2005; Laville, 2003; Jahnson, 1987).

Las empresas sociales contribuyen a dar soluciones a los problemas sociales, o a carencias en el ámbito económico, político y social (Baglioni, 2017:3530; Borzaga et al., 2017:199), y lo hacen en los siguientes términos: a) A nivel económico, ofrecen nuevas oportunidades de empleo y favorecen la innovación; b) A nivel político, vigorizan el compromiso cívico y político de la gente; c) A nivel social, ofrecen oportunidades para la socialización y la participación, contribuyendo a reconstruir el tejido social. En líneas generales, este incremento de organizaciones del tercer sector, y el mayor protagonismo de las empresas sociales de inserción laboral, implican, a su vez, un reconocimiento público de la diversidad social, de que existen necesidades diferentes entre colectivos (Bidet y Spear, 2005:198).

En España, las empresas sociales de inserción aparecieron conectadas al desarrollo económico local con la aprobación de las Comunidades Autónomas (Vidal y Claver, 2005:4). Toman impulso coincidiendo con las primeras políticas activas, y con una marcada preferencia, desde la década de los 80, por ofertar servicios de formación profesional para personas desempleadas, teniendo en cuenta que el paro afecta de manera desigual a los diferentes colectivos sociales, lo que lo hace especialmente susceptible de ser abordado localmente (Vidal y Claver, 2003:42). Al igual que en España, en Europa las empresas sociales implicadas en la inserción laboral son muy heterogéneas, y generalmente, se gestionan mediante subvenciones de las autoridades públicas. Muchas dan especial importancia a la formación o cualificación profesional, contribuyendo al desarrollo de un sentido de dignidad y de ciudadanía a través de procesos de empoderamiento, para favorecer la integración social y laboral (Bidet y Spear, 2005: 204).

En cuanto a la cuestión de qué entendemos por empresa social, una de las primeras definiciones viene de Freer Spreckly en 1981, que las definió como organizaciones que trabajan sobre bases sin ánimo de lucro, operando bajo principios democráticos y ubicadas en el ámbito local. Por su parte, para Yunus (2009) las empresas sociales maximizan una clase de negocio empleado para hacer bien a la gente, el punto principal de interés no es solo hacer dinero, sino también alcanzar objetivos sociales. En este sentido, las empresas sociales tienen una dimensión económica y otra social, y en este último aspecto su objetivo principal está en beneficiar a la comunidad, dando respuestas a carencias sociales no resueltas, y bajo un principio de distribución limitada de beneficios (Demoustier, 2005:223; Diaz Foncea y Marcuello, 2012:147). Por su parte, para Borzaga et al. (2017) cuando aumentan las desigualdades, la degradación ambiental y la turbulencia económica general, la economía social brinda a la sociedad civil los medios necesarios para satisfacer sus necesidades. En este sentido, Borzaga destaca que la economía social puede proporcionar bienes y servicios acordes con las necesidades reales de la población, teniendo en cuenta las tradiciones y valores de la cultura local. También estas empresas sociales de inserción laboral ofrecen a los desempleados más vulnerables mejores oportunidades de empleo: "facilitando una mejor formación o capacitación laboral, favoreciendo la movilidad, o mejorando la conexión entre empleadores y empleados" (Bidet y Spear, 2005:199; Vidal y Claver, 2005:3; Diaz Foncea y Marcuello, 2012:182). 
Esto no ocurre solo en España, la presencia de empresas sociales de inserción laboral se da en muchos países y en diferentes continentes. Por ejemplo, las empresas sociales están también implicadas en formación para desempleados en Japón, en concreto, Laratta y Nakagawa (2016:500-501) se refieren a las empresas que ofrecen a los discapacitados formación para el empleo, y en muchas ocasiones, en actividades que implican contacto con la población local, contribuyendo a luchar contra los prejuicios sociales. Bidet y Spear (2005:198) destacan la importancia dada a la formación para el empleo entre las actividades ejercidas por empresas de inserción laboral, debido a cambios en las habilidades requeridas para determinados empleos, que se han elevado entre todos los grupos de edad, incluyendo la aparición de nuevas profesiones. Además, siguen diciendo Bidet y Spear, se han dado cambios importantes en el Estado del Bienestar acentuando la atención hacia nuevos grupos de personas, por ejemplo, los colectivos discapacitados ${ }^{1}$, a los que se movilizan hacia el empleo. Esta realidad refuerza las interrelaciones existentes de las empresas sociales de inserción con el mercado, el Estado y la comunidad (Laratta y Nakagawa, 2016:501). En Camboya, algunas ONGs funcionan como empresas sociales para proporcionar formación para el empleo a las personas más vulnerables, en especial a personas con discapacidad (Makararavy y Anurit, 2009). Asimismo, en Pakistán se constata una mayor presencia de empresas sociales, principalmente, debido a los fracasos del gobierno para hacer frente a los problemas sociales (Yasir et al., 2016; Abbas y Arshad, 2019:1089-1090). Bidet y Spear (2005:204) hacen hincapié en que estas empresas tienen una ventaja importante para adecuar la formación al empleo frente a otros medios convencionales de relación formación y empleo, porque están más conectadas con el ámbito empresarial, y en este sentido, son más versátiles en combinar la formación y el empleo.

También el estudio de las empresas sociales conlleva el detenerse en algunos de estos aspectos: sus metas, sus objetivos, su estructura interna, las relaciones que mantienen con el gobierno, con el entramado empresarial, y con su entorno local en general (Bidet y Spear, 2005:206-207). En cuanto al tipo de recursos, y siguiendo con Bidet y Spear, se diferencia entre recursos mercantiles, los que provienen de subvenciones públicas, de trabajo voluntario, y de colaboraciones o asociaciones dentro de la comunidad. Pero, principalmente, es importante destacar el tipo de relaciones que mantienen las empresas sociales con su entorno, que varían unas de otras. Algunas de estas empresas de inserción tienen una relación más estrecha con el mercado, otras con la comunidad, y otras con el Estado, y estas relaciones determinan el tipo de recursos del que hacen uso, a la vez que influyen en sus metas u objetivos (Bidet y Spear, 2005:208).

Por último, desde principios del siglo XXI Europa está apostando por la economía social para potenciar el crecimiento económico, el empleo, y la competitividad en su lucha contra la pobreza y la exclusión social, y dentro de la estrategia Europa 2020 (Diaz Foncea y Marcuello, 2012:183), como se comentará a continuación.

1. Según Bidet y Spear (2005: 208) las primeras empresas sociales de inserción laboral se crearon para lidiar con la inserción laboral de personas con discapacidad. En Bélgica encontramos las primeras en los 60, en Francia en los 70, en Finlandia en los 80, en Portugal en los 80, en España la ONCE se fundó en 1938. Estas diferentes empresas sociales de inserción dependen mucho de sus diferentes contextos nacionales. 


\subsection{Innovación social, capital social y empresas sociales}

En el fomento de una mayor participación de las empresas sociales juega un importante papel la Unión Europea, propiciando la implicación de estas organizaciones en los programas de cohesión de políticas social y de empleo, a través de iniciativas creativas, fomentando la innovación social (Martínez Celorrio, 2015:559; Chaves y Monzón, 2018). En este sentido, Martínez Celorrio destaca que entre las prioridades de la política social y de empleo de la Unión Europea se incluye una serie de intervenciones sociales orientadas a la innovación social.

En particular, la innovación social conlleva iniciativas que buscan soluciones novedosas a problemas sociales de la forma más eficaz, eficiente y sostenible (Murray, et al., 2010; Millán y Marcuello, 2012:158). Este interés por la innovación también es una evidencia del fracaso de la mercantilización y de la privatización del Estado del Bienestar (Baglioni y Sinclair, 2014:410).

Para Martínez Celorrio (2015:549) la innovación social implica una participación más activa de la ciudadanía en una respuesta creativa y comunitaria, que nace desde abajo, aportando soluciones incluyentes ante los procesos de exclusión generados por las políticas neoliberales desde los años 90. En este sentido, Moulaert (2013) vincula la innovación social con los cambios hacia una gobernanza más democrática y de mayor justicia social. Además, se da en un contexto donde las relaciones de poder y de interacción entre Estado, mercado y ciudadanía, están siendo transformadas y redibujadas en la actual sociedad del conocimiento (Martinez Celorrio, 2015:546). En esta misma línea, Baglioni, et al. (2018:1319) destacan que la innovación social tendría que significar hacer cosas distintas, o hacerlas de forma diferente. Observan que esta innovación puede darse a nivel micro, sobre individuos o grupos particulares, a nivel meso, sobre organizaciones y comunidades, o ser abordadas desde políticas públicas a nivel macro social o supranacional.

En cuanto a la innovación social para la inclusión social, su máxima consiste en crear nuevas oportunidades educativas, laborales y de bienestar, que transformen y den soluciones a las situaciones sociales de vulnerabilidad a través de nuevas ideas, programas y actuaciones no pensadas de forma aislada por las instituciones (Martínez Celorrio, 2015:557). Sin embargo, la propia estructura administrativa puede dificultarlo, aquí se incluye una tensión potencial, 0 rivalidad, con las agencias públicas existentes (Sepúlveda, 2015:843-844), y en este sentido, el impacto de la innovación social está limitado por las condiciones estructurales y factores institucionales (Baglioni et al. 2018:1331). Esto es así, en cierto modo, porque la innovación social entra en contradicción con la verticalidad burocrática de las administraciones, que debería superarse con más flexibilidad horizontal (Martínez Celorrio, 2015:567), como se comentará más adelante en el trabajo empírico realizado en la provincia de Cádiz.

En este sentido, Murray et al. (2010) señalan que la innovación social se produce a través de una compleja red de alianzas entre las diversas partes interesadas. Es por ello que el éxito de la innovación se basa en la participación e implicación de una amplia variedad de agentes (Díaz Foncea, Marcuello y Marcuello, 2012:189). Según estos autores, se deben dar procesos participativos, confirmándose que algunos de los métodos más eficaces para fomentar la inno- 
vación social están fundamentados en el reconocimiento de que las personas son competentes y capaces para interpretar sus propias vidas y resolver sus propios problemas (Mulgan, 2006, 2007). Esto se da, especialmente, cuando se establecen relaciones sociales entre los agentes de un territorio para la resolución de estos problemas (Moulaert et al., 2005). Pero la viabilidad de las acciones de innovación social depende mucho de cada contexto, de la trayectoria histórica de las instituciones, y de la calidad de los mismos procesos de intervención (Martinez Celorrio, 2015:547). Este último autor menciona a Vale (2009), para quien la innovación ha de abordarse desde un enfoque holístico e integrado, movilizando todas las capacidades del territorio, superando el individualismo de cada organización, mediante un trabajo colaborativo, en red, que estimule la innovación.

En esta apuesta por la innovación social las empresas sociales son especialmente útiles, por ejemplo, en la adopción de medidas de innovación social que faciliten la inclusión social de personas con discapacidad. En este aspecto, cabe destacar en España la labor que puedan ejercer empresas sociales como Fundación ONCE, o la Fundación Telefónica, involucrándose en iniciativas de innovación social para la integración laboral y social de personas con discapacidad. Pero, para conocer bien las potencialidades de las empresas sociales para la innovación social es importante realizar estudios que exploren las interacciones existentes entre estas empresas sociales y sus entornos locales, de cara a perfilar mejor el diseño de estas innovaciones junto con la implementación de políticas locales (Shaw and Bruin, 2013:742). Porque los gobiernos deben incentivar la participación estrecha con una diversidad de agentes del propio sector público, del sector privado empresarial, pero principalmente, del tercer sector y de la ciudadanía (Catalá y de Miguel, 2018:126-127; Chaves y Monzón, 2018:9).

Esto lleva a destacar el enorme interés del capital social para propiciar acciones de innovación social por parte de las empresas sociales, porque el capital social favorece que estas empresas tengan acceso a recursos financieros y humanos, y en consecuencia, poder impactar en las acciones que estén llevando a cabo (Alvord, Brown y Letts, 2004). A su vez, las propias innovaciones sociales adoptadas por las empresas sociales favorecen el fortalecimiento del capital social (Abbas y Arshad, 2019). Por su parte, Shaw y Bruin (2013:743) destacan la importancia de analizar el capital social existente en las iniciativas que toman estas empresas en acciones de innovación social, particularmente útil en análisis micro-nivel. En este sentido, el capital social se considera un factor importante para favorecer el emprendimiento y la innovación. Se puede entender el capital social con referencia a los recursos de agentes sociales implicados en una red social, y que son cruciales para las iniciativas de las organizaciones (Bourdieu, 1986; Putnam, 1995; Stam et al., 2013).

Otros autores, como Catalá y de Miguel (2018:135), introducen el término de Chesbrough y Minin (2014) de Open Social Innovation, referido a una innovación social en la que la sociedad civil asume el control, que se da cuando los diferentes agentes sociales interaccionan entre sí para cooperar conjuntamente en la resolución de problemas sociales, elaborando estrategias de intervención desde la propia comunidad, pudiendo beneficiar al conjunto de la sociedad. Estas estrategias de intervenciones novedosas, construidas por agentes sociales que cooperan entre sí, tienen por objeto principal el cambio social, empoderando a la ciudadanía y con- 
tribuyendo a la solidaridad, a la cohesión social (Catalá y de Miguel, 2018: 134). Desde esta perspectiva, estos autores argumentan a favor de la Open Social Innovation como un modelo de gobernanza horizontal. Se sitúa dentro del marco conceptual del welfare mix, intentando aprovechar todos los recursos que brinda la misma sociedad.

Bajo esta perspectiva, la innovación social de la Nueva Gobernanza Pública, y del Nuevo Servicio Público (Catalá y de Miguel, 2018:129), hace que el término gobernanza represente una nueva forma de gobernar, de tomar decisiones. Su razón de ser estaría en la participación de todos los agentes implicados, que pueden incluir organizaciones públicas y privadas mediante redes sociales que son base del capital social. Se trataría de un cambio sustancial, porque se dejaría de gobernar a la sociedad para gobernar con la sociedad (De Miguel Molina, 2009:3).

Pero la realidad es mucho más compleja, porque no es fácil que las entidades públicas y privadas, implicadas en políticas públicas, alcancen el éxito en procesos de innovación social, debido a las limitaciones existentes. Catalá et al. (2020:1) reconocen que, en los procesos de innovación de políticas públicas, con implicaciones de colaboraciones públicas y privadas, el éxito o fracaso de la innovación va a depender de los factores contextuales y organizaciones que caracterizan a estas organizaciones. Se volverá de nuevo a las puntualizaciones de estos autores cuando se analicen la tipología de relaciones que mantienen las organizaciones, públicas y privadas, implicadas en la formación para desempleados en la provincia de Cádiz. Pero antes, se reflexionará sobre las repercusiones de la innovación social en el ámbito de la formación para el empleo.

\subsection{Formación para el empleo, empresas sociales e innovación educativa}

Las organizaciones del tercer sector comenzaron pronto a impartir acciones formativas para desempleados. En América latina se da una alta involucración de estas organizaciones en la formación para el empleo, principalmente Organizaciones No Gubernamentales (ONG) dirigiendo las acciones formativas a las poblaciones más excluidas (Messina, 2013:104-105). Siguiendo a Messina, en estas organizaciones la formación sirve para incentivar la participación de grupos y sujetos vulnerables, con miras a hacerlos conscientes de su situación social y personal desfavorable. También esta autora destaca las décadas de los 80 y 90 como épocas de apertura en la participación de organizaciones de la sociedad civil, configurándose muchas en empresas sociales. Este periodo es significativo en diferentes contextos, países y continentes. En España, fue a mitad de la década de los 80 y principios de los 90 cuando se aprueban programas de formación, emblemáticos para jóvenes desempleados/as con escasa o nula cualificación, como Escuelas Taller y Casas de Oficios, pero también las décadas de los 80 y 90 fue emblemática en Europa.

Fejes y Holmqvist (2019:156-157) describen las diferentes etapas por las que ha pasado la formación de adultos en Suecia (Europa) desde la década de los 50 a la actualidad, subrayando la tendencia mercantilizadora debido al incremento de participación de empresas privadas. 
Desde los 70, esta formación se desarrolla en el entorno local bajo supervisión municipal. Pero antes, tras la II Guerra Mundial, Suecia tenía una industria potente que demandaba trabajadores más cualificados, y esto hizo que el discurso sobre la formación para el empleo se centrara, a mediados de la década de los 50 y década de los 60, en proporcionar formación para el trabajo a potenciales trabajadores caracterizados por disponer de altas capacidades. En cambio, desde 1971 se ponen las miras en otra tipología de alumnado, dirigiéndose la atención a los colectivos más alejados del mercado laboral, con más bajos niveles educativos. Posteriormente, ya en la década de los 90 se aprueba una nueva reforma de la educación de adultos en Suecia, ajustada a un discurso de gerencia pública y a la vez mercantilizada. A partir de entonces se da un mayor poder a los municipios para seleccionar, en concurrencia competitiva, a las organizaciones destinadas a impartir acciones formativas, participando en estas convocatorias empresas con y sin ánimo de lucro. Esta participación de empresas para la formación de adultos en Suecia se ha incrementado sustancialmente en las últimas décadas. Fejes y Holmqvist (2019:157) destacan que en 1997 el 14,4\% del total de las organizaciones que impartían cursos eran del sector no público, pero en 2016 la proporción asciende al 45\%, lo que refleja un rápido incremento de la privatización.

En el caso de América Latina se pone especial atención, principalmente a partir de 1990, en ofertas formativas para grupos marginados que apenas existían en décadas anteriores, y en este sentido, se multiplican los programas formativos para estas poblaciones, tanto en zonas rurales como urbanas (Messina, 2013:105; Pieck, 2000). Además, si bien la formación para el trabajo en Latinoamérica nació de la mano del Estado y de la iglesia, han ido ganando posiciones las ONGs de todo tipo, hasta el punto que estas organizaciones trabajan, la mayoría de ellas, con programas de formación para el empleo (Messina, 2013). Por su parte, Jacinto (2016) estudia el papel desempeñado por las organizaciones de la sociedad civil en la inserción laboral de jóvenes con baja cualificación en Argentina. Destaca que también a partir de los 90 se aprecia una mayor participación de estas organizaciones en la implementación de políticas activas de empleo, tratándose de organizaciones del tercer sector que funcionan como empresas sociales, como fundaciones, federaciones, cooperativas.

Esta misma participación de organizaciones del tercer sector se da también en países de otros continentes. En Camboya, algunas organizaciones no gubernamentales se constituyen como empresas sociales para favorecer la inserción laboral de personas desempleadas, dirigiendo sus servicios, mayoritariamente, a los colectivos más vulnerables como las personas con discapacidad, mediante acciones formativas para el empleo (Makararavy y Anurit, 2009:24-26). Asimismo, en Japón hay organizaciones de la sociedad civil que desde la década de los 60 ofertan formación profesional a discapacitados, muchas de estas organizaciones se convirtieron en empresas sociales a partir de 1981 (Laratta y Nakagawa, 2016).

Por otro lado, volviendo al caso español, Serrano, Fernández y Artiaga (2012:49) mencionan la participación de organizaciones de la sociedad civil en la implementación de los programas de formación e inserción laboral para los desempleados más vulnerables. Analizaron las intervenciones de las siguientes organizaciones en los programas de inserción laboral: Cáritas, Cruz Roja, AVAPE, Eslabón y Fundación Forja XXI. Según estos autores, estas entidades, mu- 
chas funcionando como empresas sociales, se caracterizan por intervenciones más flexibles, individualizadas y descentralizadas, siendo simbólicamente indicativas de un nuevo modelo de gobernanza.

En este contexto, la formación para el empleo se diseña para responder a las necesidades de cualificación laboral demandadas por las empresas, pero también está contribuyendo a una formación integral que enriquezca a la persona en sus aspectos sociales y personales, dada la situación de precariedad laboral que caracteriza el mercado de trabajo. Esto es especialmente importante considerando que la inserción laboral puede representarse como un proceso largo, complejo y contradictorio, al que se vuelve una y otra vez, dada la precariedad del empleo, siendo especialmente delicada la situación de los colectivos adultos más vulnerables (Messina, 2013:113). En este sentido, se subraya el interés por innovaciones sociales y educativas que contribuyan a la inserción laboral, pero también personal y social del desempleado/a.

En este último aspecto, la innovación social pretende ser una forma de empoderar a la gente, especialmente a colectivos desfavorecidos a través de un compromiso activo en la iniciativa de cambio (Borzaga y Bodini, 2012:5). También en la formación para el empleo se referencia a la innovación educativa, y se recoge la observación de Silveira (1998:15-16), de finales de los 90, de que la formación ha de atender a objetivos técnicos de cualificación laboral, pero también ha de formar en el "saber ser", tan importante para el desempeño profesional. Particularmente, las innovaciones educativas han sido propuestas por organismos internacionales y Estados nacionales, con diseños y puestas en práctica promovidos de arriba abajo, buscando generalizar el modelo en otros contextos (Messina, 2013:98-99). Este esquema de innovación educativa, según esta autora, cambia en la década de los 90 , de tal modo que, de centrarse en algo nuevo para generalizarse a otros contextos se empieza a expandir la idea de volcarse en la comunidad, apostando por una iniciativa innovadora que conecte con las particularidades del entorno local.

En ocasiones, las iniciativas locales de innovación educativa derivan de organizaciones no gubernamentales que se constituyen en empresas sociales, mientras que los organismos gubernamentales, por contraste, adoptan, en su mayoría, un enfoque de abordaje neoliberal de arriba abajo (Messina, 2013:111). Es importante destacar, en cuanto a estas innovaciones educativas, que cuando son promovidas por organizaciones internacionales no gubernamentales, o bien, por entidades de la sociedad civil, suelen contribuir más y mejor a crear lo que Messina y Pieck (2007) llaman experiencias significativas. Este término significa algo más que una mera innovación educativa, al tratarse de iniciativas innovadoras que buscan ser significativas para los sujetos, antes que centrarse meramente en las metas marcadas por el programa formativo, impuesto por instancias superiores. Dicho de otro modo, las experiencias significativas, como iniciativas más ambiciosas que la mera innovación educativa, llevan a un desplazamiento de los intereses institucionales hacia las personas (Pieck, 2012; Messina, 2013:102). Las innovaciones educativas se caracterizan por un enfoque centrado en el aprender haciendo, en cambio, las experiencias significativas buscan una formación no limitada al trabajo, empoderando a individuos y grupos con base a proyectos educativos integrales, privilegiando la participación y adaptando la formación a las necesidades locales. 
En lo que respecta a los proyectos llevados a cabo como experiencias significativas, se insiste especialmente en los que realizan ONGs que operan a nivel local, y que funcionan, con frecuencia, manteniendo relaciones fluidas entre el ámbito público y el privado en beneficio de la comunidad (Messina y Pieck, 2008). De este modo, se lograría ese ideal al que se refieren Billett y Seddon (2006:57) de que las organizaciones del tercer sector, que operan a nivel local en la formación profesional, favorezcan a la comunidad.

Por otro lado, en Suecia la educación de adulto, impartida casi en un 50\% por empresas privadas, con o sin ánimo de lucro, y supervisadas por los municipios (administración, en representación del Estado), tiene el compromiso de proveer a los desempleados con oportunidades para desarrollar sus conocimientos y competencias, con objeto de fortalecer su posición en el trabajo, pero también su vida social para contribuir así a su desarrollo personal (Fejes y Holmqvist, 2019:162). Según Fejes y Holmqvist, esta formación debe ayudar a los adultos participantes a tomar parte activa como ciudadanos, a la vez que los prepara para el mercado de trabajo. Los objetivos que recoge la formación de adultos en Suecia refuerzan la importancia que tiene el adoptar iniciativas innovadoras, en línea con la definición dada por Messina y Pieck de "experiencias significativas". Esta definición de experiencias significativas es especialmente importante en el diseño de la formación profesional para personas desempleadas, porque entre sus colectivos se incluyen sectores muy vulnerables que necesitan, tanto como la inserción laboral, mejorar su integración con la comunidad.

Además, el concepto de experiencia significativa también conecta con la definición de innovación social abierta (Chesbrough and Minin, 2014), entendida como una innovación de abajo arriba, en la que la sociedad civil colabora activamente en la resolución de sus problemas. Esto es especialmente importante cuando pensamos en colectivos vulnerables, como es el caso de los desempleados que reciben formación para el empleo en la provincia de Cádiz. En esta provincia encontramos organizaciones públicas y privadas impartiendo formación para desempleados, destacando empresas sociales como Fundosa de la ONCE, Cáritas, Cruz Roja, Fegadis -Federación de discapacitados físicos y orgánicos- y empresas de formación e inserción laboral. En las siguientes secciones se presentará la metodología de la investigación, seguida de los resultados obtenidos del análisis de la tipología de organizaciones implicadas en esta formación, haciendo especial hincapié en las que son empresas sociales. Se analizarán las relaciones que mantienen estas organizaciones entre sí, con la administración (Estado), el mercado, y la escasa relación con la comunidad; en particular, se resaltarán algunos de los factores que pueden dificultarlas en la toma de iniciativas de innovación social.

\section{Metodología de Investigación}

La investigación empírica sobre la formación profesional para desempleados se realizó en 2018 en la provincia de Cádiz, centrada en dos objetivos principales: b) Analizar la tipología de organizaciones que imparten esta formación, confirmando la relevancia de las empresas sociales, y b) Analizar los elementos que dificultan que estos centros de formación adopten 
iniciativas de más autonomía y cooperación entre ellos, siguiendo algunos de los supuestos teóricos desarrollados en las secciones anteriores, partiendo de estudios que destacan que la cooperación entre organizaciones favorece las iniciativas de innovación.

\section{Tabla 1. Técnicas de Investigación utilizadas}

\section{Técnicas Cuantitativas}

Encuesta elaboración propia.

Cuestionario enviado por correo electrónico a los centros colaboradores de la Junta de Andalucía en la provincia de Cádiz en 2018.

\section{Técnicas Cualitativas}

Organizaciones de Formación públicas y privadas:

12 entrevistas en profundidad en la siguiente tipología de centros:

a) Dos entrevistas en Organizaciones No Gubernamentales.

b) Tres entrevistas en Federaciones de discapacitados físicos y mentales, respectivamente.

c) Dos organizaciones públicas: Diputación, Cámara de Comercio.

d) Tres Empresas privadas de formación, de éstas, dos son también de inserción.

e) Una entrevista a Confederación de Empresarios de Cádiz.

f) Una entrevista a un representante sindical.

Técnica de Análisis de fuente secundaria cuantitativa -censo de centros

7 entrevistas focales a diferentes colectivos de desempleados vulnerables:

1. Un grupo de desempleados con discapacidad mental.

2. Grupo desempleados con discapacidad física.

3. Dos grupos desempleados menores o igual a 30 años.

4. Un grupo desempleados heterogéneos en edad y nivel educativo.

5. Un grupo de varones de 18 a 44 años.

6. Un grupo desempleados de parados de larga y muy larga duración.

Análisis puntual de las páginas Web de las organizaciones entrevistadas para analizar sus contactos empresariales. cuantitativas sobre cifras paro y tasa temporalidad en la provincia.
Análisis puntual de fuentes secundarias

En la Tabla 1 se detallan las técnicas de investigación cuantitativa y cualitativa que se han utilizado para este trabajo. La primera, la encuesta, aporta información relevante sobre las relaciones que mantienen estos centros con el programa formativo de la Junta de Andalucía, recogida en los ítems del cuestionario sobre los mecanismos de control y modelo de subvención. El cuestionario se envió por correo electrónico a todos los centros colaboradores de la provincia en 2018, que eran 364, respondiendo el 20\% del total (74 cuestionarios cumplimentados). Esta información sobre los centros se completa con el análisis de fuente secundaria del censo de centros colaboradores en la provincia en 2020, disponible en la página Web de la Consejería². También, y de forma puntual, se recabó información de algunas de las páginas Webs de los centros entrevistados para conocer las empresas que las patrocinan.

2. Mapa de registro de centros colaboradores de Formación para el Empleo de la Junta disponible en: https:// www.juntadeandalucia.es/empleoformacionytrabajoautonomo/oficinavirtualFPE/Macenco/ 
Respecto a la metodología cualitativa, se incluyen 12 entrevistas en profundidad realizadas a diferentes organizaciones públicas y privadas, representativas de la tipología de centros de formación para desempleados en la provincia, y que son las siguientes: organizaciones tradicionales (sindicatos y asociaciones empresariales), empresas sociales (federaciones de discapacitados, fundación, empresas de formación e inserción, organizaciones no gubernamentales), y organizaciones de la administración pública (administración local y autonómica). Estas entrevistas se realizaron, junto con las 7 entrevistas focales al alumnado desempleado, a partir de preguntas abiertas similares para todos los centros y grupos de desempleados, respectivamente. De las entrevistas focales a las diferentes tipologías de desempleados vulnerables, según discapacidad, género y edad, solo se utilizan en este trabajo los resultados obtenidos en torno a las dificultades sociales y laborales percibidas por los desempleados. Las 19 entrevistas fueron grabadas y posteriormente transcritas. La información obtenida del análisis de las transcripciones se clasificó en códigos ${ }^{3}$ y categorías, recogidos en la Tabla 2.

\section{Tabla 2. Categorías y códigos de análisis}

\begin{tabular}{|c|c|}
\hline Categorías & Códigos \\
\hline $\begin{array}{l}\text { Valoraciones sobre el programa } \\
\text { formativo de la Junta de Andalucía. }\end{array}$ & $\begin{array}{l}\text { - Homologación del local y especialidades formativas. } \\
\text { - Controles de la Junta sobre los centros colaboradores. } \\
\text { - Modelo de subvención de la Junta. }\end{array}$ \\
\hline $\begin{array}{l}\text { Relaciones con la administración y } \\
\text { con otras entidades. }\end{array}$ & $\begin{array}{l}\text { - Relación con organizaciones similares. } \\
\text { - Relación con organizaciones distintas. } \\
\text { - Relación con empresarios. } \\
\text { - Relación con la administración. }\end{array}$ \\
\hline $\begin{array}{l}\text { Valoraciones sobre los programas } \\
\text { formativos en los que participan. }\end{array}$ & $\begin{array}{l}\text { - Formación de los programas operativos del FSE. } \\
\text { - Formación del SEPE del Ministerio. } \\
\text { - Programa formativo PICE de Cámara de Comercio. } \\
\text { - Programa SIAP, que gestiona el Servicio Andaluz de } \\
\text { Empleo. }\end{array}$ \\
\hline \multicolumn{2}{|c|}{ ENTREVISTAS FOCALES: Grupos Desempleados Vulnerables } \\
\hline Sentimientos de exclusión social. & $\begin{array}{l}\text { - Incomprensión por parte de familiares y amigos. } \\
\text { - Ausencia de una rutina que organice su vida diaria. }\end{array}$ \\
\hline $\begin{array}{l}\text { Opiniones generales sobre el } \\
\text { mercado laboral. }\end{array}$ & $\begin{array}{l}\text { - Inestabilidad laboral (y dificultad inserción). } \\
\text { - Exigencias continuas de formación laboral. }\end{array}$ \\
\hline
\end{tabular}

3. Como señala Cáceres (2003:65), cada código requiere de una definición precisa para explicar el alcance del mismo, que se recoge en sus correspondientes segmentos de texto, pero las limitaciones de un artículo impiden este desarrollo pormenorizado por código. Sin embargo, se hará referencia a los segmentos de textos, correspondientes a estos códigos, en la sección de discusión de resultados. 


\subsection{Categorías de análisis de las entrevistas}

El trabajo empírico parte de los supuestos teóricos desarrollados en las primeras páginas, como guía para el análisis de las transcripciones de las entrevistas a los centros. Algunas de las investigaciones comentadas en secciones anteriores indican que las relaciones de cooperación de las organizaciones entre sí y con su entorno, propician la innovación. Con relación a estas investigaciones, en el análisis de los datos se hace referencia a cómo la estructura administrativa, y en general, los factores institucionales y las relaciones entre organizaciones, limitan las iniciativas de innovación social. El punto de referencia empírico lo dan las categorías y sus correspondientes códigos, obtenidos del análisis de las transcripciones, vinculados a los supuestos teóricos anteriores. En este particular, la construcción de categorías nos acerca y orienta en el conocimiento de aspectos concretos de la realidad analizada, pasando a ser reconocidos como propiedades del fenómeno social estudiado, a la vez que pueden aportar información nueva no contenida en los supuestos teóricos iniciales (Cáceres, 2003:69-70).

Los datos empíricos en cualitativa nos acercan a la comprensión de un determinado fenómeno social, contribuyendo a una aproximación teórica sobre dicho fenómeno (Vivar et al., 2010). También es importante lo que apunta Páramo (2015:x) de que las investigaciones pueden desarrollarse en un área en la que no existen explicaciones teóricas suficientes y completamente satisfactorias, como es el tema de la innovación social. Esta observación hace que sea fundamental el contexto como elemento a tener en cuenta en el análisis de los datos o de la información recabada. Se entiende el contexto "como una unidad de contenido mayor, al que se hace referencia para comprender las unidades de análisis, considerado desde el momento de selección del universo de estudio" (Briones, 1988, citado por Cáceres, 2003:73).

Por otro lado, la metodología utilizada se ajusta a los criterios de triangulación inter-método y triangulación de datos, al abordar una misma temática de investigación a partir de técnica cuantitativa y cualitativa (encuesta, entrevistas en profundidad, y análisis cuantitativo), lo que implica enriquecer los resultados con el análisis de datos de diferentes metodologías, con el fin de contrastar observaciones sobre un mismo tema o fenómeno (Forni y De Grande, 2020:166).

\section{Resultados de la Investigación}

El contexto se considera primordial para poder interpretar los resultados de la investigación, partiendo del hecho de que en la provincia de Cádiz se da una alta tasa de paro y de empleo temporal que dificultan el éxito de estas acciones formativas para la inserción laboral, a la vez que complica la consecución de objetivos más sociales de integración social. Según la EPA (Encuesta de Población Activa), la tasa de temporalidad en la provincia de Cádiz llegó a casi el $36 \%$ en 2019, y el Instituto Nacional de Estadística situaba la tasa de paro de la provincia en torno al 27\%, en octubre de 2019. 
A continuación, y tomando como trasfondo este contexto, se exponen los resultados, comenzando por el análisis cuantitativo del censo de centros colaboradores en la provincia que recoge la Tabla 3, distinguiendo los centros según tipología. En este particular, se subraya que, en España, en las últimas décadas, se ha dado un cambio muy significativo en la tipología de organizaciones implicadas en esta formación. El primer programa de formación profesional para desempleados fue a mitad de la década de los ochenta del siglo XX, en 1985, gestionado, inicialmente por al antiguo INEM (Instituto Nacional de Empleo). En sus inicios, estas acciones formativas fueron ejecutadas íntegramente por la administración pública, sin participación de empresas privadas. Desde entonces a la actualidad se ha dado un incremento considerable de la participación de las empresas privadas y de otras organizaciones, como federaciones de discapacitados, organizaciones no gubernamentales, y principalmente, empresas de formación e inserción laboral que funcionan como empresas sociales.

\section{Tabla 3. Centros Colaboradores de la Junta de Andalucía en la provincia de Cádiz en 2020}

\begin{tabular}{|c|c|c|}
\hline Tipología de centro & № total de centros & $\%$ de Centros \\
\hline $\begin{array}{l}\text { Empresas privadas: autoescuelas, hoteles, } \\
\text { peluquerías, industria cárnica, etc. }\end{array}$ & 40 & 11,8 \\
\hline Centros de Formación y de inserción laboral & 159 & 47 \\
\hline Centros educativos: Colegios e institutos públicos. & 44 & 13 \\
\hline $\begin{array}{l}\text { Centros representación empresarial: ASAJA, } \\
\text { Confederación Empresarios, Cámara de Comercio, } \\
\text { etc. }\end{array}$ & 21 & 6,2 \\
\hline Centros Sindicales: Sólo CC.OO. & 5 & 1,5 \\
\hline $\begin{array}{l}\text { Administración Municipal y Mancomunidades } \\
\text { y Fundaciones: concejalía, consorcio, complejo } \\
\text { municipal, fundaciones, biblioteca... }\end{array}$ & 39 & 11,5 \\
\hline $\begin{array}{l}\text { Centros de la Sociedad Civil. Residencias de } \\
\text { ancianos, centro de acogida, centro cívico, } \\
\text { asociación cultural, recreativa (algunas } \\
\text { dependientes del Ayuntamiento). }\end{array}$ & 14 & 4 \\
\hline $\begin{array}{l}\text { Organizaciones No Gubernamentales y } \\
\text { Fundaciones. Tierras de Todo, Cruz Roja, atención a } \\
\text { la inmigración. }\end{array}$ & 7 & 2 \\
\hline $\begin{array}{l}\text { Centros de Discapacitados. Asociación autismo, } \\
\text { asociación minusválidos, Centros ocupacionales, } \\
\text { unidad estancia diurna. }\end{array}$ & 10 & 3 \\
\hline Total & 339 & 100 \\
\hline
\end{tabular}

Fuente: Elaboración propia a partir del Mapa de Registro de Centros Colaboradores de la Junta de Andalucía. 
En 2020 se contabilizaba en esta provincia un total de 339 centros colaboradores, unos 30 centros menos que en 2018. De la información recabada en 2020 destaca que el 47\% de total de centros corresponde a empresas de formación e inserción laboral, muchas funcionando como empresas sociales de inserción laboral. Cerca del 12\% de los centros corresponde a empresas privadas, como hoteles, autoescuela, peluquerías, industria cárnica. También es significativo que un $13 \%$ de centros colaboradores correspondan a instituciones educativas, entre los que se encuentran colegios e institutos públicos. Además, es importante destacar la reducida participación de los sindicatos, resultando casi insignificante, y de organizaciones empresariales (6,2\% del total de centros), entre los que se encuentran ASAJA, Confederación de Empresarios, y Cámara de Comercio. Esta baja participación de asociaciones empresariales, y de organizaciones sindicales, contrasta con la alta participación de centros pertenecientes al sector privado, con o sin ánimo de lucro, como son las empresas sociales.

Siguiendo con los datos contenidos en esta Tabla 3, los centros colaboradores correspondientes a la administración pública suponen el 11,5\% del total, incluyendo centros homologados a consistorios, consorcios, mancomunidades, biblioteca municipal, complejo municipal, y algunas fundaciones correspondientes a locales que la Junta ha aprobado a los ayuntamientos. Por otro lado, un $4 \%$ del total de centros se integran en el ámbito de la comunidad o sociedad civil, comprendiendo a residencias de ancianos, centros de acogidas, asociaciones culturales y recreativas. Le siguen, aunque con menor participación, los centros de discapacitados y las organizaciones no gubernamentales, en torno al 3\% y $2 \%$ respectivamente, cifras demasiado pequeñas teniendo en cuenta la referencia que hace la normativa de $2017^{4}$ de contribuir a la inserción laboral de los desempleados más vulnerables, entre los que se incluyen los discapacitados.

Se desglosan a continuación los resultados obtenidos de las técnicas de investigación cuantitativa y cualitativa en torno a los dos objetivos principales. En un primer apartado, se mencionan los resultados relativos a la tipología de centros que imparten formación para desempleados, con especial referencia a las organizaciones que funcionan como empresas sociales. En un segundo apartado, se detallan algunas de las características del funcionamiento de estas organizaciones, que las limitan en su autonomía para la toma de iniciativas propias o de cooperación para la innovación social.

En cuanto a la tipología de organizaciones implicadas, con especial relevancia de las empresas sociales, los resultados más destacados son los siguientes:

1. En torno al $60 \%$ de los centros colaboradores de la Junta de Andalucía en la provincia de Cádiz son empresas, y de este total se da una mayor participación de empresas sociales, principalmente empresas de formación e inserción laboral (47\% de los centros colaboradores).

2. La mitad de las 12 organizaciones públicas y privadas entrevistadas son empresas sociales: dos federaciones de discapacitados, 2 empresas de formación e inserción laboral y dos organizaciones no gubernamentales. Estos centros son representativos de la

4. La resolución del 14 de diciembre 2017 de la Dirección General de la Formación Profesional para el Empleo, relativo a la selección del alumnado participante en las acciones formativas. 
tipología de organizaciones que funcionan como empresas sociales, implicados en la formación para desempleados en la provincia.

3. Las 6 empresas sociales disponen de mayores recursos de personal, y complementan las acciones formativas para desempleados con otros servicios de asesoramiento e inserción laboral, en mayor medida que las otras organizaciones.

4. Estas empresas sociales mantienen más y mejores contactos con las empresas. En sus páginas Webs se recoge información de sus empresas colaboradoras.

5. Estas empresas sociales, por los propios colectivos vulnerables con los que trabajan, tienen más posibilidades que otras organizaciones para mantener contactos con la comunidad local (ONGs, federaciones, fundaciones, entre otras).

Respecto al segundo objetivo, con relación a los atributos o elementos encontrados que dificultan a los centros para adoptar medidas más creativas, como son las iniciativas de innovación social, se destacan los siguientes hallazgos:

1. Los resultados de la encuesta a los centros colaboradores indican que el programa formativo de la Junta establece unos controles demasiado estrictos sobre la homologación de centro y especialidades formativas, además, los centros valoraban negativamente el modelo de subvención. Estas valoraciones negativas fueron confirmadas también en las entrevistas en profundidad.

2. Por tanto, el modelo formativo de la Junta refuerza la relación jerárquica de la administración sobre los centros colaboradores de formación, limitando el margen de maniobra para iniciativas propias y de cooperación entre organizaciones.

3. También se confirman relaciones de competencia y de escasa cooperación entre las organizaciones implicadas en la formación para desempleados.

4. Los centros de formación en la provincia de Cádiz participan en diferentes programas formativos para desempleados (programas operativos del Fondo Social Europeo, a nivel autonómico, del Servicio Andaluz de Empleo, del Ministerio, entre otros). Estos se caracterizan por ajustarse a convocatorias muy puntuales, centradas, principalmente, en incentivar los contactos con las empresas locales, descuidándose otras estrategias que podrían fomentar la cooperación entre organizaciones, y que favorecerían la creación de capital social.

5. Por último, y no menos importante, las entrevistas focales a diferentes colectivos de desempleados vulnerables confirmaban que existe un serio problema social en torno a estos desempleados, que no se resuelve ofertando acciones formativas puntuales, encaminadas a una inserción laboral incierta, dadas las altas tasas de paro y de trabajo temporal en esta provincia de Cádiz.

La siguiente sección aportará más detalles sobre las relaciones que mantienen estas organizaciones, contribuyendo a comprender mejor algunas de sus dificultades para la autonomía y la cooperación, y, por tanto, para la innovación social. La discusión de resultados parte, principalmente, de la información recabada de las 12 entrevistas a los centros de formación, públicos y privados, subrayando la importante participación de las 6 empresas sociales. Por último, se concluirá haciendo referencias a la información obtenida de las 7 entrevistas focales 
a colectivos desempleados vulnerables, teniendo en cuenta que estas acciones formativas van dirigidas, preferentemente, a los desempleados más vulnerables.

\subsection{Discusión de Resultados}

Los resultados de la investigación realizada en la provincia de Cádiz confirman la presencia de elementos que dificultan a las organizaciones, implicadas en la formación para desempleados, para la creación de iniciativas de innovación social. La investigación es especialmente relevante, teniendo en cuenta que tras la crisis económica de 2007/2008, principalmente por parte de la Unión Europea, se confirma una apuesta firme por la innovación social (Martínez Celorrio, 2015:563; Chaves y Monzón, 2018). Como se argumentó en secciones anteriores, la innovación considera las particularidades del territorio, con la colaboración conjunta de organizaciones públicas y privadas, para dar soluciones más estables a los problemas sociales como el desempleo y la exclusión social. Los supuestos teóricos desarrollados en las primeras páginas se relacionan aquí con la información recabada en el trabajo empírico, a partir de las siguientes categorías de análisis obtenidas del examen de las transcripciones de las entrevistas: A) Valoración de los centros sobre el programa formativo de la Junta de Andalucía. B) Relaciones jerárquicas que mantienen con la administración. C) Relaciones horizontales que mantienen con organizaciones similares, y con otra tipología de centros. D) Características de los programas formativos en los que participan y que pueden limitarlas. Por último, se recogen algunas afirmaciones sobre cómo perciben los desempleados vulnerables entrevistados la inserción laboral.

Empezando por la primera categoría, los centros de formación entrevistados hicieron una valoración negativa del programa formativo de la Junta. Destacaban el endurecimiento de los requisitos de homologación de local y de especialidades formativas, pero también valoraban negativamente el modelo de subvención. El director de una academia de formación expresaba su malestar refiriéndose al periodo posterior a la crisis 2007-2008, remarcando que en la Junta se había dado un "parón de la formación, y claro, un montón de centros cerrados, una situación bastante insostenible, nada de cursos hasta 2016". Otro de los entrevistados observaba situaciones de descoordinación entre la Junta de Andalucía y el Servicio Andaluz de Empleo (SAE). También los técnicos de formación de la delegación provincial reconocían, coincidiendo con otros entrevistados, que los mecanismos que aplica la Junta para el control de gastos habían mejorado, pero en cambio, los criterios de homologación de local y de especialidad formativas se han hecho demasiado estrictos. A este respecto, puntualizaban que un número significativo de ayuntamientos no había podido homologar su local, a pesar de que: "tampoco veían la necesidad de tantos requisitos para una formación que a saber cuánto durará", dándose la paradoja, según uno de los técnicos entrevistado, de que:

La planificación de cursos de formación se ha hecho más rígida, porque se pueden detectar necesidades formativas de las empresas, pero mientras se solicita esta formación a la Junta, y se aprueba, pueden pasar dos años. 
Las federaciones de discapacitados físicos, y la federación de enfermos mentales, también mantenían evaluaciones negativas hacia el programa formativo de la Junta, insistiendo en que los requisitos de homologación son ahora más estrictos. Del mismo modo que las organizaciones empresariales, Confederación de Empresarios y Cámara de Comercio, subrayando que los centros más perjudicados habían sido las academias de formación. Las valoraciones negativas hacia este programa de formación de la Junta quedaron también confirmadas en la información recabada mediante encuesta. Casi la mitad de los centros, un 46,51\%, se sentía bastante 0 muy insatisfecho con el modelo de financiación. Por otro lado, del total de centros encuestados tan sólo el 30\% valoraba de forma positiva el seguimiento que hacía la Junta sobre la labor de inserción laboral seguida por los centros, frente al 40\% de insatisfechos o muy insatisfechos. Además, en una de las entrevistas se afirmaba que estos cursos de formación no se adecuan a las particularidades de los colectivos más vulnerables, como expresaba el técnico de una 0NG:

A estos cursos de la Junta no pueden acceder los colectivos vulnerables de la organización, porque son cursos demasiado largos, porque para alguien que necesita urgentemente una solución a sus problemas económicos esta formación no está nada adaptada.

Respecto a las relaciones jerárquicas entre organizaciones y Administración se incluyen varios niveles: las que mantienen con la Junta, con la administración central, mediante el programa formativo del SEPE (Servicio de Empleo Estatal), del Ministerio, y con programas operativos del Fondo Social Europeo, o con Inserta, de Fundosa de la ONCE. Siguiendo con el programa de formación de la Junta, la federación de discapacitados físicos puntualizaba lo siguiente: "La baremación, los criterios del tipo de alumnado, los CV de los monitores, etc. Todo esto lo controla la Junta". Este mismo control de la administración se observaba en otras convocatorias de cursos de formación para desempleados. En concreto, el director de una de las academias se refería a los criterios marcados por la convocatoria de cursos de formación de Fundosa en los siguientes términos:

Fundosa abre una convocatoria que dice: quiero impartir un curso de ofimática en Jerez que tenga 330 horas, horario mañana, 15 alumnos. Nosotros tenemos que hacer el programa formativo, presentarles los tutores del curso, una simulación de cómo sería una clase, un proyecto bastante completo. Fundosa lo valora, lo puntúan y aprueba, si lo considera. Fundosa busca los alumnos, no tenemos que buscarlo.

Esta dinámica de funcionamiento de la formación para colectivos desempleados, sujeta a convocatorias, hace que el centro supedite las acciones formativas a los criterios marcados, a pesar de que esta mecánica de funcionamiento consigue una insuficiente inserción laboral del alumnado. Por otro lado, es importante reconocer que la empresa social Inserta de la ONCE, como organización de formación e inserción, recibe una valoración positiva por parte de las demás Federaciones de discapacitados, que la reconocen como una entidad potente, que trabaja muy bien, con ofertas exclusivas para personas con discapacidad. Pero no deja de ser una 
formación muy puntual, elaborada con arreglo a convocatorias de acciones formativas que abre la empresa, en concurrencia competitiva, a la que pueden presentarse otras empresas en un plazo determinado, sujeta a los requisitos marcados por la organización.

Del mismo modo, las acciones formativas del SEPE (Servicio de Empleo Público Estatal) que imparten algunas de estas organizaciones, también están sujetas a convocatorias, ajustadas al cumplimiento de unos requisitos. Esta limitación de la formación para el empleo queda patente en la siguiente situación vivida, expresada por el técnico de una academia pequeña de formación, de ámbito local:

Realizamos dos cursos de un proyecto que presentamos a una convocatoria del SEPE, por el Sistema Nacional de Garantía Juvenil. Decían que teníamos más puntos si presentábamos el programa en dos comunidades simultáneas y desfavorables, así que lo presentamos con una academia de Canarias, y ganamos.

Justamente las convocatorias de cursos de formación para el empleo del Ministerio empezaron a ser significativas con posterioridad a la crisis del 2008, y según el entrevistado, era una formación a la que ellos no podían acceder, porque, por lo general, solo daban cabida a academias de formación de un ámbito territorial más amplio. A partir de 2018 se produjeron cambios en este aspecto, permitiendo que otras academias locales pudieran presentarse a estas convocatorias.

También se han analizado las relaciones horizontales entre organizaciones, distinguiéndose las que mantienen los centros colaboradores de la misma tipología y las que mantienen con otros centros distintos al suyo. Destacan algunas diferencias significativas entre centros, las academias pequeñas de formación cooperan motivadas por los requisitos marcados por la convocatoria de cursos del $\mathrm{SEPE}^{5}$, como se comentó más arriba. En cambio, las federaciones de discapacitados colaboran entre sí intercambiándose usuarios, ya que trabajan con diferente tipología de personas con discapacidad, manteniendo una relación especialmente importante con Fundosa de la ONCE.

Se dan también relaciones horizontales entre organizaciones diferentes, en este caso, entre academias de formación y organizaciones no gubernamentales mediante el acuerdo de que la academia de formación imparta en su propio local la acción formativa de la ONG, a cambio de una cuantía económica acordada por ambos. En muchas ocasiones, la propia organización no gubernamental se ve avocada a ello por no disponer de un local adecuado para la formación.

Pero en líneas generales, los resultados obtenidos apuntan a que estas organizaciones están más limitadas por las relaciones jerárquicas con la administración, y por los requisitos que marcan las convocatorias de las acciones formativas. Además, algunos de los entrevistados reconocían que se dan situaciones de competencia entre centros de formación, uno de los técnicos lo expresaba con estas palabras:

5. La Resolución del Servicio Público de Empleo Estatal -SEPE- del 26 mayo de 2014, especifica que podrán impartir esta formación, financiado con fondos públicos, entidades públicas y privadas, siempre que dispongan de centros propios, y cumplan con los requisitos que se les exigen en la indicada modalidad presencial o de teleformación. 
La Cámara de Comercio es una empresa privada, actúan como empresa privada, totalmente. Es una competencia, vaya, al igual que la confederación de empresarios, vaya. De hecho, yo sé que en Córdoba se han presentado a la convocatoria de cursos de Fundosa. Y Diputación, por ejemplo, saca un curso, pues por detrás está el SEPE o la Junta, no hay otra; y Fundosa es una empresa, vaya. A nivel público está Sepe o la Junta, punto.

Esta competencia entre las organizaciones implicadas en la formación para desempleados contrasta con la necesidad de creación de capital social, entendiéndose como paso previo a la creación de innovación social, por lo que parece prioritario reducir las situaciones de competencia entre organizaciones con objeto de fomentar la cooperación. En este sentido, Billett y Sedon (2006:57) destacan la importancia de que los programas de formación sigan una estrategia encaminada a fortalecer el capital social, favoreciendo las redes de contactos que sostengan la confianza y cooperación entre los agentes sociales implicados, mejorando el aprendizaje, pero también sirviendo al centro como incentivo para la innovación, a la vez que motiva a los individuos que reciben la formación. En esta misma línea, y en un trabajo más reciente, Carbonara y Pellegrino (2018:257) afirman que, para propiciar la innovación se debe mejorar la cooperación y la confianza entre los socios involucrados en las colaboraciones públicas y privadas.

Otro aspecto importante que dificulta la adopción de iniciativas creativas de innovación social está en el hecho de que se fomenta, ante todo, que el centro de formación mantenga relaciones estrechas con las empresas de la zona, siendo estas las únicas relaciones que se incentivan para la realización de las acciones formativas dirigidas a los colectivos desempleados, descuidándose otras relaciones que propiciarían mejorar la integración social de los desempleados más vulnerables dentro de la comunidad.

En este sentido, las empresas sociales ${ }^{6}$ entrevistadas mantienen, principalmente, dos tipos de relaciones con las empresas privadas y con algunas otras empresas sociales:

a) Empresas privadas que patrocinan a estas organizaciones en los programas operativos ${ }^{7}$ del Fondo Social Europeo, cubriendo el 25\% de gastos, completando el $75 \%$ que aporta el Fondo Social Europeo, y que incluye empresas muy diversas ${ }^{8}$.

6. Las organizaciones analizadas participaban en varios programas de formación para desempleados. En buena medida, la crisis de 2007-8 paralizó la oferta de cursos de formación de la Junta de Andalucía, tomando mayor protagonismo los cursos del SEPE (Servicio Estatal Público de Empleo), de la administración central. También se reforzaron las iniciativas de ofertas formativas de organizaciones no gubernamentales ONGs, como es el caso de las ONG Cruz Roja y Cáritas, y de las federaciones de discapacitados, destacando el protagonismo de Inserta de la ONCE. Estas organizaciones pertenecen a la Confederación Empresarial Española de Economía Social (CEES).

7. Se dan acciones formativas dentro del Programa Operativo de Inclusión Social y Economía Social (POISES), del Fondo Social Europeo, en el que participaban las empresas sociales entrevistadas. Destacan también los cursos de formación para el empleo del Servicio Integral de Atención a las Pymes (SIAP), y el Programa Integral de Cualificación y Empleo (PICE) por iniciativa de la Cámara de Comercio, y con el apoyo del Sistema Nacional de Garantía Juvenil del Ministerio.

8. ONCE, BBVA, Santander, OHL, Vodafone, Iberdrola, Caixa, entre otras. 
b) Empresas privadas colaboradoras, que establecen convenios de prácticas para alumnado de cursos de formación para el empleo, en algunos casos con compromiso de inserción laboral ${ }^{9}$.

Estas relaciones muestran una dependencia con el mercado, ámbito de actuación mucho más fortalecido en los diversos programas de formación para desempleados analizados, en detrimento de las relaciones con el ámbito comunitario o de la sociedad civil, retomando de nuevo el planteamiento teórico del triángulo de Pestoff. En este sentido, el funcionamiento de estos programas de formación se limita, principalmente, al objetivo de la inserción laboral, aunque con poco éxito. De hecho, en las entrevistas realizadas a los diferentes centros de formación se reconocían que la inserción laboral conseguida era temporal e insuficiente.

También hay que tener en cuenta que las iniciativas de innovación social en la formación profesional para desempleados pueden ir encaminadas a incentivar el espíritu empresarial. En relación a esto, y como posible estrategia, Shikalepo (2019:133) observa que la formación para el empleo ha tendido a organizarse sólo con el propósito de que el desempleado encuentre empleo, y ha descuidado el importante objetivo de que la formación sea un medio para que el alumno llegue a ser un innovador de oportunidades de negocio, a partir de la formación recibida.

Para Baglioni et al. (2018:1319), la innovación social no es sólo encontrar soluciones alternativas a las grietas dejadas por el sector público y el mercado, sino hallar las mejores formas para empoderar a la gente, especialmente a grupos desfavorecidos, a través del compromiso activo en el proceso innovador. Pero los procesos de innovación se ven afectados por determinados factores, entre los que destacan la estructura del mercado, las relaciones que establecen las propias organizaciones implicadas, y los apoyos gubernamentales (Carbonara y Pelligrino, 2020; Catalá et al., 2020). En este sentido, el análisis de la información recabada en la investigación realizada en la provincia de Cádiz muestra que las organizaciones están limitadas por controles administrativos, como los criterios que marcan las convocatorias de formación. Se trata, además, de una formación para desempleados encaminada, de forma muy puntual, a satisfacer las necesidades de pequeñas y medianas empresas de la zona. A pesar de que la inserción laboral conseguida sea insuficiente, y descuidando el hecho de que esta formación está dirigida, principalmente, a desempleados vulnerables, que se encuentran, con frecuencia, con situaciones de rechazo laboral y social.

Este rechazo fue expresado por los desempleados entrevistados en las 7 entrevistas focales realizadas a colectivos vulnerables, siendo especialmente significativo entre las personas desempleadas con discapacidad por enfermedad mental. Este colectivo se quejaba del desconocimiento de la gente hacia su discapacidad, del estigma que sentían, y de los estereotipos que hay en la calle sobre la enfermedad mental. Pero también los desempleados con discapacidad física expresaban descontento por la incomprensión percibida por parte de los empresarios y de su entorno social más cercano; al igual que los parados de larga duración y mayores de 45 años.

9. Algunas de estas empresas, para el caso de Cruz Roja y Cáritas, son: El Corte Inglés, Carrefour, Endesa, Repsol, Obra Social la Caixa, Airbus, Bricodepot, Ikea, Prenatal. 
Todos estos colectivos se lamentaban de que no tener un trabajo les limita en su vida social, y les agota (en expresión de una desempleada mayor de 45 años, compartida por todo el grupo), ya que no trabajar significa la ausencia de rutina, vista como necesaria para organizar sus vidas cotidianas. Además, eran conscientes, coincidiendo los siete grupos de alumnado entrevistado, de que el mercado laboral está en continuo cambio y existe mucha competencia, y por ello, se sienten, con frecuencia, compitiendo los jóvenes con los que tienen más experiencia, en tanto que los parados de larga duración han de rivalizar con jóvenes muy preparados.

Estos resultados apuntan a la importancia de adoptar estrategias que vinculen la formación, no sólo a las necesidades de los empresarios locales, también a las necesidades de la comunidad, haciendo partícipes a los propios desempleados y a su entorno en la construcción de soluciones formativas vinculadas a la creación de empleo, con objeto de vehicular realmente la formación con un trabajo decente. Una posible vía sería planificar la formación para desempleados dentro de estrategias de innovación social o educativa que trabajen, por ejemplo, en línea con lo que Messina llama "experiencias significativas".

Otra alternativa sería la propuesta de innovación de Shikalepo (2019:133) de una formación para el empleo que incentive al alumnado a ser innovador de oportunidades de negocios, a partir de la formación recibida. Pero la formación para desempleados, tal como está planteada en la actualidad, parte de un enfoque individualista y mercantilista que asienta la responsabilidad en el propio individuo, y enfocada de forma unilateral al mercado. Desde esta perspectiva se descuidan las limitaciones del contexto, de la necesidad de crear incentivos para los desempleados, y por supuesto, de las propias limitaciones de la estructura burocrática y de las organizaciones que han sido abordadas en este trabajo empírico. A continuación, se hará una recapitulación de todo lo analizado, destacando los resultados de la investigación, e incluyendo otras reflexiones.

\section{Conclusiones e Implicaciones}

Este trabajo se ha centrado en el importante papel que asumen organizaciones públicas y privadas en la impartición de acciones formativas para desempleados, resaltando el protagonismo de las empresas sociales. La participación de empresas sociales, y demás organizaciones públicas y privadas en la formación para el empleo, significa, en buena medida, un nuevo modo de afrontar el problema del desempleo, representado en las relaciones entre el Estado, el mercado y las organizaciones del tercer sector. Es lo que Pestoff $(1995,2008)$ recoge en su triangulo del Estado del Bienestar, posicionando en el centro a las organizaciones del tercer sector, entre las que se sitúan, preferentemente, empresas sociales de formación e inserción laboral, ofreciendo formación para el empleo a los colectivos desempleados más vulnerables.

Se ha analizado la tipología de centros implicados en esta formación, comprobando la alta participación de empresas de formación e inserción laboral, junto con organizaciones no gubernamentales y federaciones de discapacitados. También se detalló cómo las organizaciones implicadas mantienen relaciones jerárquicas con instancias administrativas superiores, 
y priorizan sus relaciones con las empresas locales. Además, se evidenciaron relaciones de competencia entre algunos centros, y escasa cooperación entre ellos. Se confirmó mediante las entrevistas que la inserción laboral conseguida era insuficiente, teniendo en cuenta que se trata de una zona geográfica con alta tasa de paro.

Respecto a la información recabada en las entrevistas focales a desempleados vulnerables, estos colectivos expresaron encontrarse en situaciones de exclusión social y laboral, lo que lleva a poner el énfasis en la importancia de adoptar medidas de formación para el empleo más integradoras. Considerado, además, que en la actualidad es un objetivo prioritario la innovación social, como se recoge en la agenda de la Unión Europea. La innovación social comprende iniciativas, según Murray et al. (2010), que buscan soluciones novedosas a problemas sociales. Esto conlleva que las políticas de empleo, y en este caso concreto la formación para el empleo, según algunos de los autores consultados, han de establecer iniciativas vinculadas a la comunidad, y no sólo con las empresas. En este sentido, se puede trabajar integrando las acciones formativas dentro de una estrategia de cambio más amplia, encaminada a fortalecer los lazos comunitarios, además de ampliar las posibilidades de una inserción laboral más sostenible en el tiempo. Por ejemplo, adoptando medidas que vinculen la formación a otras etapas de un proceso de cambio que lleven a iniciativas destinadas a la creación de empleo estable.

En cuanto a la innovación social vinculada a la cooperación entre las organizaciones, existen pocos estudios que profundicen en qué aspectos concretos son vinculantes al éxito de este tipo de iniciativas, considerando las particularidades de cada territorio. Faltan investigaciones que encaucen a una perspectiva teórica más detallada sobre las características existentes entre una mayor cooperación entre organizaciones y la innovación social, que lleven realmente a soluciones novedosas frente al problema del paro. Fundamentalmente, porque el planteamiento teórico sobre la innovación social se ha construido desde arriba, desde instituciones supranacionales como la Unión Europea, y son necesarias las investigaciones concretas, que analicen las particularidades del territorio, para profundizar en los elementos que dificultan y favorecen la innovación.

Se mencionan, a continuación, algunas de las limitaciones de la investigación realizada en la provincia de Cádiz. En primer lugar, los resultados de las técnicas cualitativas, mediante entrevistas en profundidad, y entrevistas focales, son representativos de una zona geográfica con alta tasa de paro, pero no son extrapolables a otros territorios más dinámicos y con baja tasa de desempleo. En segundo lugar, se desconocen las similitudes y diferencias según provincia en la representación de tipología de organización, públicas y privadas, implicadas en la formación para desempleados en Andalucía, y lo que puede significar en su relación con la administración, las empresas locales, y con entidades de la sociedad civil. La tercera limitación se constata en el hecho de que no se profundiza en las características particulares de cada tipología de organización, y de sus relaciones con los desempleados. Cabe mencionar otra limitación de la investigación, al no haberse analizado los objetivos que los centros se marcan al participar en acciones formativas para desempleados, porque podrían priorizar vincular los cursos de formación a los intereses particulares de la organización, con planificaciones a corto plazo, ajustadas a los intereses de su entidad. Por último, en cuanto a la técnica de la encuesta, 
se envió el cuestionario a todos los centros colaboradores en la provincia de Cádiz, contestando el 20\% del total, por este motivo solo se ha utilizado información relativa a los centros agregados, sin hacer distinciones por tipología de centros.

Este trabajo, además, propone varias líneas de investigación. Se plantea la necesidad de estudiar las relaciones posibles entre la formación para el empleo y el desarrollo sostenible, considerando que la educación para la inclusión social es objetivo prioritario en la Agenda 2030 de Desarrollo Sostenible (2015). En este aspecto, también la innovación social vuelve a ser importante, porque desde una perspectiva del desarrollo sostenible la formación para desempleados supondría trabajar la integración social, e inserción laboral, encaminándolas a la creación de empleos estables ${ }^{10}$. Esto no se puede conseguir de forma automática en una zona con alta tasa de paro, así que la innovación social vuelve a ser prioritaria.

Otra línea de investigación estaría en analizar cómo se han ido incorporando estas empresas sociales a la formación profesional para desempleados, viendo su evolución en las últimas décadas en España, y realizando estudios comparativos entre distintas comunidades autónomas, y con otros países, haciendo distinción entre las diversas empresas sociales participantes, ONGS, Federaciones de discapacitados, como Fundosa de la ONCE, y de empresas de formación e inserción. Esta línea de investigación nos permitiría conocer mejor las relaciones entre los cambios sociales y económicos, junto con los cambios políticos en la gestión de políticas activas de empleo, como la formación para desempleados. Además, el mismo hecho de introducir la innovación social, como un nuevo reto de política de empleo, marca una diferencia con el modelo de gerencia pública, basado en la competencia y lógica del mercado (Voorberg y Bekkers, 2018:711, citados por Catalá y de Miguel, 2018:129), dando cabida a objetivos conjuntos de desarrollo social y económico. Justamente, este trabajo parte de la importancia de relacionar el desarrollo social y económico, centrando el texto en analizar algunos aspectos que dificultan la innovación social, junto con los factores que pueden fomentarla, considerando las particularidades del territorio.

\section{Financiación}

Plan de fomento a la investigación de la Universidad de Cádiz para 2017-2018.

10. La Agenda 2030 de Desarrollo Sostenible, publicada por Naciones Unidas en 2015, que comprende 17 objetivos, dedica el objetivo 4 a la educación inclusiva, y el objetivo 8 a promover el empleo decente y el desarrollo económico, sustentable, sostenible e inclusivo. 


\section{Bibliografía}

ABBAS, J., ARSHAD, Darwina, SUBRAMANIAM, Ch. (2019): "Social Capital and Social Enterprise Performance in Pakistan. Social Innovation as a Proposed Mediator", Social Science and Humanities Journal, 3(4), 1089-1095. https://sshj.in/index.php/sshj/article/view/364.

ALVORD, Sarah, BROWN, David \& LETTS, Christine (2004): "Social entrepreneurship and societal transformation. An exploratory study", The Journal of Applied Behavioral Science, 40(3), 260-282. DOI: $10.1177 / 0021886304266847$.

BAGLIONI, Simone, CHABANET, Didler \& PERSSON, Thomas R. (2018): "The rise of social enterprises and social entrepreneurship in Western". In: Social Entrepreneurship and Social Innovation. Ecosystems for inclusion in Europe, Routledge Taylor and Francis Group. London and New York, 24-37.

BAGLIONI, Simone, MAZZEI, Micaela, SINCLAIR, Stephen \& ROY, Michael J. (2018): "Social Innovation, Social enterprise, and local public services: undertaking transformation", Social Policy and Administration, 52(7), 1317-1331. D0I: https://doi.org/10.1111/spol.12389.

BAGLIONI, Simone (2017): "A Remedy for All Sins? Introducing a Special Issue on Social Enterprises and Welfare Regimes in Europe", VOLUNTAS: International Journal of Voluntary and Nonprofit Organizations, 28, 2325-2338. D0I: https://doi.org/10.1007/s11266-017-9929-y.

BAGLIONI, Simone \& SINCLAIR, Stephen (2014): "Introduction Social Innovation and Social Policy", Social Policy \& Society, 13(3), 409-410.

DOI: https://doi.org/10.1017/S1474746414000177.

BIDET, Eric \& SPEAR, Roger (2005): "Social Enterprise for Work Integration in 12 European Countries: A descriptive Analysis", Annals of Public and Cooperative Economics, 76(2), 195-231. Available at: https://ssrn.com/abstract=739381.

BILLETT, Stephen \& SEDDON, Terri (2006): “Bulding Community through Sopcial Partnershipos around Vocational Education and Training", Journal of Vocational Education and Training, 56(1), 51-68. DOI: 10.1080/13636820400200245.

BRIONES, Guillermo (1988): Métodos y Técnicas avanzadas de Investigación aplicada a la Educación y las Ciencias Sociales, Curso de Educación a Distancia, Bogotá: Corporación Editorial Universitaria.

BROMLEY, Patricia, SCHOFER, Eva \& LONGHOFER, Wesley (2018): “Organizing for education: A cross-national, longitudinal study of civil society organizations and education outcomes". International Journal of Voluntary and Nonprofit Organizations, 29, 526-540.

DOI: $10.1007 /$ s11266-018-9979-9. 
BOURDIEU, P. (1986): “The forms of capital”. In: J. Richardson (Ed.) Handbook of Theory and Research for the Sociology of Education, New York: Greenwood, 241-258.

BORZAGA, Carlo, SALVATORI, Gianluca y BODINI, Riccardo (2017): La Economía Social y Solidaria y el Futuro del Trabajo, OIT, Ginebra.

Disponible en: http://www.socioeco.org/bdf_fiche-document-6343_es.html.

BORZAGA, C. \& BODINI, C. (2012): "What to make of social innovation? Toward a framework for policy development", Euricse Working Paper, 036/12. Trento, EURICSE. Available at: https://ideas.repec.org/p/trn/utwpeu/1236.html.

CÁCERES, Pablo (2003): "Análisis cualitativo del contenido: Una alternativa Metodológica Alcanzable", Psico-perspectivas. Revista de la Escuela de Psicología, 2(1), 53-82.

CARBONARA, Nunzia \& PELLEGRINO, Roberta (2020): "The role of public private partnership in fostering innovation", Construction Management and Econmics, 38(2), 140-156.

DOI: https://doi.org/10.1080/01446193.2019.1610184.

CARBONARA, Nunzia \& PELLEGRINO, Roberta (2018): "Fostering innovation in public procurement through public private partnerships", Journal of Public Procurement, 18(3), 257-280. https://doi.org/10.1108/J0PP-09-2018-016.

CATALÁ, Daniel y MIGUEL MOLINA, María de (2018): “La Innovación Social como modelo de gobernanza de las políticas sociales en el marco del paradigma colaborativo de la Open Innovation" - Actas del VII Congreso de la Red Española de Política Social (REPS): Políticas sociales ante horizontes de incertidumbre y desigualdad, 4 y 5 de octubre de 2018, Zaragoza. Coords. Alessandro Gentile, Ana Lucía Hernández Cordero, Borja Miranda Larré.

CATALÁ, Daniel, RASK, Mikko, MIGUEL, María de (2020): "The Demola model as a public policy tool boosting collaboration in innovation: A comparative study between Finland and Spain", Technology in Society, 63(101358), D0I: https://doi.org/10.1016/j.techsoc.2020.101358.

CHAVES, Rafael \& MONZÓN, José Luis (2018): “The social economy facing emerging economic concepts: social innovation, social responsibility, collaborative economy, social enterprises and solidarity economy", CIRIEC-España, Revista de Economía Pública, Social y Cooperativa, 93, 5-50. DOI: 10.7203/CIRIEC-E.93.12901.

CHESBROUGH, Henry \& DI MININ, Alberto (2014): “Open Social Innovation”. In: Chesbrought, H., W. Vanhaverbeke, W. y West, J. New Frontiers in Open Innovation, Oxfort: Oxford University Press, 169-188.

DEFOURNY, Jacques \& NYSSENS, Marthe (2012): "Conceptions of Social Enterprise in Europe: A comparative Perspective with the United States". In B. Gidron \&Y. Hasenfeld (eds.), Social Enterprise. An Organizational Perspective, Palgrave Macmillan, New York. 
DEFOURNY, Jacques \& PESTOFF, Victor (2014): “Toward a European Conceptualization of the Third Sector". In L.P. Costa \& M. Andreau (eds.), Accountability and Social Accounting for Social and Non-Profit Organizations: Advances in Social Accounting, Vol. 17, Bingley, UK: Emerald Group Publishing Limited, 1-61.

DEMOUSTIER, Danièle (2005): "Las empresas sociales: ¿nuevas formas de Economía Social en la creación de servicios y empleos?", CIRIEC-España, Revista de Economía Pública, Social y Cooperativa, 52, 219-236. Disponible en:

https://econpapers.repec.org/article/cicrevcir/y_3a2005_3ai_3a52_3ap_3a219-236.htm.

DE MIGUEL MOLINA, Maria (2009): "E-Government in Spain: An Analysis of the Right to Quality E-Government", International Journal of Public Administration, 33(1), 1-10.

DOI: https://doi.org/10.1080/01900690903178454.

DÍAZ-FONCEA, Millán y MARCUELLO, Carmen (2012): “Las empresas Sociales en España: Concepto y Características", GIZAEKOA, Revista Vasca de Economía Social, 8, 143-164.

DÍAZ-FONCEA, Millán; MARCUELLO, Carmen y MARCUELLO, Chaime (2012): “Empresas sociales y evaluación del impacto social", CIRIEC-España, Revista de Economía Pública, Social y cooperativa, 75, 179-198.

EVERS, Adalbert (1995): "Part of the welfare mix: The third sector as an intermediate área", Voluntas: International Journal of Voluntary and Nonprofit Organizations, 6(2), 159-182, from http://www.jstor.org/stable/27927470

FEJES, Andreas \& HOLMQVIST, Diana (2019): "Procurement as a market in adult education”. In Neoliberalism and Market Forces in Education: Lessons from Sweden, Routledge, London, 156169.

FORNI, Pablo \& DE GRANDE, Pablo (2020): “Triangulación y métodos mixtos en ciencias contemporáneas", Revista Mexicana de Sociología, 82(1), 159-189.

DOI: http://dx.doi.org/10.22201/iis.01882503p.2020.1.

JACINTO, Claudia (2016): "Redefiniendo la Empleabilidad en los programas de formación e inserción laboral de jóvenes. El rol de las organizaciones de la sociedad civil". En: Faur, E. (compiladora), Repensar la Inclusión Social. Políticas públicas y sociedad civil en Argentina (19912016), Fundación Tzedaka-Capital Intelectual.

JOHNSON, Norman (1987): Welfare State in Trasition, University of Massachusetts Press, Massachusetts.

LARATTA, Rosario \& NAKAGAWA, Sachiko (2016): "Work Integration Social Enterprises for People with Disabilities in Japan”, Nonprof Pol Forum, 7(4), 487-507. 
LAVILLE, Jean Louis (2003): "Childcare and Welfare Mix in France", Annals of Public and Comparative Economics, 74(4), 591-630. D0I: https://doi.org/10.1111/j.1467-8292.2003.00237.x.

MAKARARAVY, Ty \& ANURIT, Pacapol (2009): "Impacts of training and Development on Social Enterprises in Cambodia", NIDA Development Journal, 49(2), 24-38. DOI: 10.14456/ ndj.2009.19

MARTÍNEZ CELORRIO, Xavier (2015): La innovación social ante los desafíos del Bienestar. Informe España 2015, Fundación Encuentro, Madrid.

MESSINA, Graciella (2013): "En busca de un lugar para mirar las innovaciones de formación para el trabajo". Em: Cleunice REHEM e Irma BRIASCO (coord.), Formación Profesional y Empleo. Publica OEI Organización de Estado Americano, 95-114.

MESSINA, Graciella \& PIECK, Enrique (2007): "Meaningful experiences: reconceptualizing best practices", Paper 12. NORRAG. Paris, France.

MESSINA, Graciella y PIECK, Enrique (2008): “Educación y trabajo: una mirada a la práctica en sectores marginados de América Latina". Em: Messina, Pieck y Castalleda (eds), Educación y trabajo; lecciones desde la práctica innovadora en América Latina, UNESCO / Chile. Disponible en: https://unevoc.unesco.org/fileadmin/user_upload/docs/innovemos.pdf.

MOULAERT, Frank \& AILENEI, Oana (2005): "Social Economy, Third Sector and Solidarity Relations: a conceptual synthesis from History to Present", Urban Studies, 42(11), 2037-2053. DOI: https://doi.org/10.1080\%2F00420980500279794.

MOULAERT, Frank (ed.) (2013): The International Handbook on Social Innovation, Cheltenham: Edward Elgar Publishing.

MULGAN, Geoff (2006): "The Process of Social Innovation", Innovations: Technology, Governance, Globalization, 1(2), 134-162.

MULGAN, Geoff (2007): Social Innovation: What it is, why it matters and how it can be accelerated, Young Foundation, London.

MURRAY, Robin, CAULIER-GRICE, Julie \& MULGAN, Geoff (2010): The open book of social innovation, The Young Foundation, London.

PÁRAMO MORALES, Dogoberto (2015): “La Teoría Fundamentada (Grounded Theory), metodología cualitativa de investigación Científica”, Pensamiento \& Gestión, 39, vii-xiii.

PESTOFF, Victor (1998): Beyond the market and State. Civil Democracy and Social Enterprise in a Welfare Society, Aldershot, Ashgate.

PESTOFF, Victor (2008): A democratic architecture for the welfare state, Routledge, London. 
PIECK, Enrique (2012): La sistematización de experiencias significativas de formación para el trabajo de los ICAT, ICAT -Instituto de Capacitación para el Trabajo de la Ciudad de México, México.

PIECK, Enrique (2000): “Educación de jóvenes y adultos vinculada al trabajo”. En: La educación de personas jóvenes y adultos en América Latina y El Caribe. Prioridades de acción en el siglo 21, UNESCO, Santiago de Chile.

PUTNAM, Robert D. (1995): “Bowling alone: America's declining social capital”, Journal of Democracy, 6(1), 65-78.

SERRANO PASCUAL, Amparo, FERNÁNDEZ RODRÍGUEZ, Carlos J. y ARTIAGA LEIRAS, Alba (2017): "Ingenierías de la subjetivación: el caso de la orientación para el empleo", REIS, Revista Española de Investigaciones Sociológicas, 138(1), 41-62. D0I: 10.5477/cis/reis.138.41.

SEPÚLVEDA, Leandro (2015): "Social Enterprise. A New Phenomenon in the Field of Economic and Social Welfare?", Social Policy \& Administration, 49 (7), 842-861.

DOI: https://doi.org/10.1111/spol.12106.

SILVEIRA, Sara (1998): "La educación para el trabajo: un nuevo paradigma”. Seminario sobre La educación como instrumento para superar la pobreza y el desempleo, Ciudad de Panamá, 5 al 7 de agosto de 1998.

SHAW, Eleonor and BRUIN, Anne de (2013): "Reconsidering capitalism: The promise of social innovation and social entrepreneurship", International Small Business Journal, 31 (7), 737-746. DOI: https://doi.org/10.1177\%2F0266242613497494.

SHIKALEPO, Elock Emvula (2019): "Sustainability of Entrepreneurship and Innovation among VET Graduates in Namibia", International Journal for Innovation Education and Research, 7(5), 133-145. D0I: https://doi.org/10.31686/ijier.Vol7.Iss5.1484.

STAM, Wouter, ARZLANIAN, Souren and ELFRING, Tom, (2013): "Social capital of entrepreneurs and small firm performance: A meta-analysis of contextual and methodological moderators", Journal of Business Venturing, 29, 152-173. D0I:10.1016/j.jbusvent.2013.01.002.

SPRECKLEY, Freer (1981): Social Audit. A Management Tool for Co-operative Working, Beechwood College, Leeds (UK).

UNITED NATIONS (2015): The 2030 agenda for sustainable development. https://sustainabledevelopment.un.org/post2015/transformingourworld

VALE, Ana (2009): “A New Paradigm for Social Intervention”. In: AAVV. Social Innovation. Sociedade e Trabalho Booklet, MTSS, Lisboa. 
VIDAL, Isabel \& CLAVER, Nuria (2005): Work Integration Social Enterprises in Spain. Work Book, 4. EMES European Research Network

VIDAL, Isabel \& CLAVER, Nuria (2003): "Las empresas sociales en el ámbito de la integración por el trabajo", CIRIEC-España, Revista de Economía Pública, Social y Cooperativa, 46, 39-62.

VIVAR, Cristina, ARANTZAMENDI, María, LÓPEZ-DICASTILLO, Olga \& GORDO, Cristina (2010): "La teoría fundamentada como metodología de Investigación Cualitativa en Enfermería", INDEX de Enfermería. 19(4), 283-288.

VOORBERG, William \& BEKKERS, Victor (2018): "Is Social Innovation a Game Changer of Relationships Between Citizens and Governments?". In: Ongaro, E. \& Van Thirel, S. (eds). Handbook of Public Administration and Management in Europe, Palgrave Macmillan, London UK, 707-725.

YASIR, Muhammad, IMRAN, Rabia, IRSHAD, Muhammad \& KHAN, Muhammad (2016): "Leadership Styles in Relation to Employees Trust and Organizational Change Capacity: Evidence From Non-Profit Organizations", SAGE Open, 6(4), 1-12. DOI: 10.1177/2158244016675396.

YUNUS, Muhammad (2009): Creating a world without poverty: social business and the future of the capitalism, Public Affairs, Philadelphia. 